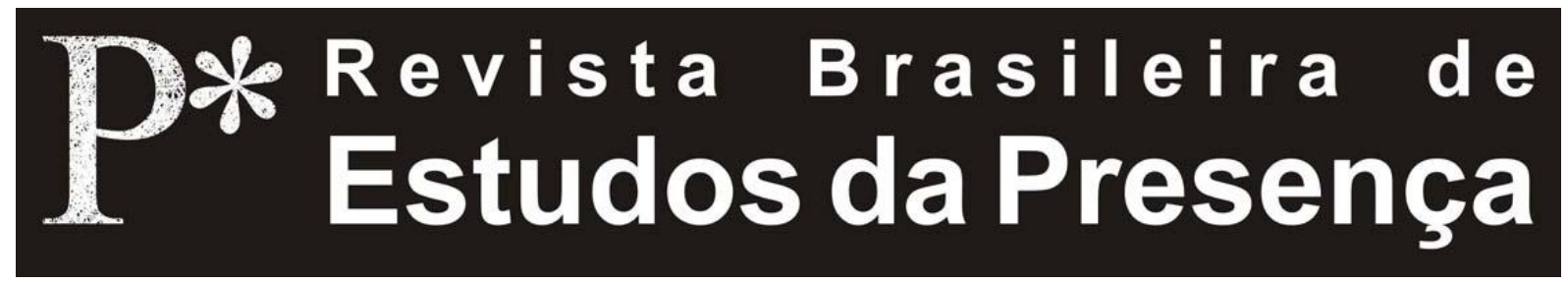

\title{
Si vis me flere. Emoções pelo espelho
}

\author{
Clelia Falletti \\ Università di Roma 1 La Sapienza - Itália
}

\begin{abstract}
RESUMO - Si vis me flere. Emoções pelo espelho - Este texto aborda a questão do trabalho do ator por intermédio de elementos das neurociências e da filosofia. Apresenta-se textos de Horácio nos quais haveriam indicações aos atores e oradores. Trama-se tais pressupostos com textos de Diderot e Copeau para fazer emergir compreensões sobre as emoções e as tarefas mais racionais do trabalho do ator. Apresenta-se o conceito de mecanismo espelho para mostrar como os neurônios espelho do cérebro são responsáveis por ações em cadeia no sistema nervoso. Compara-se tais mecanismos ao trabalho do ator.
\end{abstract}

Palavras-chave: Ator. Teatro. Neurociências. Mecanismo Espelho. Presença.

ABSTRACT - Si vis me flere. Emotions in the mirror - This paper addresses the issue of the actor's work with the aidof elements from neurosciences and philosophy. It presents texts by Horace in which he gives indications to actors and speakers. Suchassumptions are elaborated with texts by Diderot and Copeau in orderto raise comprehensions about the emotions and more rational tasks ofthe actor's work. It presents the concept of mirror mechanism to showhow mirror neurons in the brain are responsible for chain actions inthe nervous system. It compares those mechanisms with the actor'swork.

Keywords: Actor. Theatre. Neurosciences. Mirror Mechanism. Presence.

RÉSUMÉ - Si vis me flere. Émotions à travers le miroir - Ce texte aborde la question du travail de l'acteur dans la perspective des neurosciences et de la philosophie. Il s'appuie sur des textes d'Horace contenant des indications aux acteurs et orateurs. Ces présupposés sont ensuite croisés avec des textes de Diderot et de

Clelia Falletti, Si vis me flere. Emoções pelo espelho.

R.bras.est.pres., Porto Alegre, v.1, n.2, p. 286-300, jul./dez., 2011.

Disponível em http://www.seer.ufrgs.br/presenca 
Copeau pour faire émerger une réflexion sur les émotions et sur les tâches les plus rationnelles du travail de l'acteur. Présentant le concept de mécanisme-miroir, l'auteur montre comment les neurones miroir du cerveau sont responsables des actions en chaine qui se produisent dans le système nerveux. Enfin, il propose de mettre ces mécanismes au profit d'une analyse sur le travail de l'acteur.

Mots-clés: Acteur. Théâtre. Neurosciences. Mécanisme-Miroir. Présence.

O famoso hemistíquio horaciano é um pouco mais do que um pretexto ou uma alusão para aproximar-me de um nó central e tão pouco indagado nos estudos teatrais, a relação entre o ator e o espectador, que hoje pode receber nova luz pelas descobertas recentes das ciências neurofisiológicas e cognitivas.

Si vis me flere. O que quer dizer Horácio com esta frase: se queres que eu chore? Ela continua e se conclui no verso seguinte: dolendum est/primum ipsi tibi, seria: para se deixar atingir, primeiro deve ser você? Para causar dor, primeiro deve ser você? (Orazio, 1983, p. 102-103).

E, sobretudo, a quem se dirige? Para um ator. Bem, então, Horácio diz para um ator: se você quer que eu chore -, com aquilo que vem depois.

Há uma tradição muito longa, a partir do Humanismo e da Renascença, de comentadores para os quais essa frase, extraída de seu contexto original, soava como uma recomendação para os atores de teatro. Mais tarde ainda, nos séculos XVII e XVIII, nos debates filosóficos sobre as teorias das emoções e os atores, a frase de Horácio era muitas vezes repetida para definir a posição daqueles que pensavam que os atores deveriam identificar-se com os estados mentais dos personagens que representavam - uma batalha histórica jamais concluída entre os defensores da técnica e os defensores da inspiração nas teorias do ator.

Nem todos estavam de acordo, é claro. No século XVIII, o debate acirrou-se também graças ao grande ator inglês David Garrick que se apresentou várias vezes nos salões na França. Famosa é a descrição que faz Diderot em torno de 1773 em seu Paradoxe sur le comédien, após

Clelia Falletti, Si vis me flere. Emoções pelo espelho.

R.bras.est.pres., Porto Alegre, v.1, n.2, p. 286-300, jul./dez., 2011.

Disponível em http://www.seer.ufrgs.br/presenca 
ter visto David Garrick fazer uma demonstração de uma sequência de estados emotivos em uma rápida sucessão, em um Salão de Paris em 1767:

Garrick enfia a cabeça entre as duas metades de uma porta e, no espaço de quatro ou cinco segundos, o seu rosto passa sucessivamente de uma alegria imensa a uma alegria moderada, dessa para a tranquilidade, da tranquilidade para a surpresa, da surpresa ao estupor, do estupor à tristeza, da tristeza ao abatimento, do abatimento ao terror, do terror ao horror, do horror ao desespero, e aumenta desse último estágio para aquele do qual havia diminuído. Será por acaso que a sua mente foi capaz de experimentar todas essas sensações e executar, em conjunto com o seu rosto, aquela espécie de escala musical? Eu não acredito nisso, e nem vocês. [...] É possível rir e chorar à vontade? Não. É possível fazer a careta mais ou menos fiel, mais ou menos ilusória, dependendo se é ou não Garrick (Diderot, 1960, p. 40).

Quem acreditava que o ator se identificasse com os estados de ânimo por representá-los se perguntava: como é possível que um ser humano possa realmente ir de um sentimento para outro, com controle? $\mathrm{O}$ ator que pode fazer isso pertence, então, a uma raça diferente da humana (uma raça de desregrados, a serem excluídos pelo poder judiciário) ou, simplesmente, é um mentiroso, um falso, um desonesto, indigno de confiança (e, portanto, igualmente colocado à margem: não possuíam os mesmo direitos civis dos outros, não podia testemunhar, não eram sequer sepultados em solo sagrado). O exemplo de virtuosismo de Garrick, ao contrário, serve a Diderot como prova de que o ator não sente verdadeiramente aquilo que mostra, mas domina suas paixões e com lucidez e inteligência é capaz de compor e tornar a sangue frio a gama dos sentimentos que exprime ${ }^{1}$.

No século XVII, o acirramento das controvérsias e das discussões indica um fervor de interesses em direção ao problema da expressão física das paixões ou da encarnação física da mente interior, que enchem os tratados do século XVII que abordam a retórica, a psicologia e a medicina. Nesse debate, o ator se torna o campo privilegiado de investigação e experimentação no

Clelia Falletti, Si vis me flere. Emoções pelo espelho.

R.bras.est.pres., Porto Alegre, v.1, n.2, p. 286-300, jul./dez., 2011.

Disponível em http://www.seer.ufrgs.br/presenca 
qual as sutilezas das paixões são mais evidentes, talvez, poderíamos dizer ironicamente - porque aqui é mais fácil trazer experiências pessoais e pessoas sãs de bom senso, elas mesmas - se vai ver - a partir de Quintiliano, sempre fazem evitar os binarismos do discurso, confundindo aquilo que é o comportamento cotidiano com a organização artística dos materiais de sua arte.

Em que contexto Horácio diz aquela frase? Ele fala disso na epístola aos Pisoni, ou, para muitos, simplesmente, A poética de Horácio. No segundo livro das Epístolas, escrito em 13 a.C., sobre o encerrar de sua atividade como poeta, a tendência à regularidade, à pedagogia, está mais diretamente explícita. E os ensinamentos nessa epístola são contínuos. Um dos dois Pisoni (dedicatórias da carta) tem intenção de debruçar-se sobre a poesia dramática e isso é o suficiente para que Horácio se ocupe dessa forma de arte. Na epístola (um verdadeiro registro de preceitos e, portanto, sendo utilizada mais tarde, no final da Idade Média e no Renascimento), ele insiste principalmente sobre os princípios da harmonia (que é também a unidade da obra), da conveniência e do longo aperfeiçoamento.

A nossa frase parece adequada quando o poeta latino fala do segundo princípio e enquanto ilustra aquilo que convém ao menos para a poesia dramática (para a tragédia o estilo trágico e as palavras sérias, para a comédia o estilo leve e alegre), surge uma lacuna: fala ao poeta, mas, a seguir, ao descrever aquilo que se convém, faz um deslocamento repentino e diante dos olhos se apresenta um rosto sorridente e um rosto triste. Ele diz:

[...] não basta que a poesia seja 'bela'. Deve dar alegria, deve conduzir o nosso espírito para onde ele sinta prazer. Da mesma forma que, para um rosto risonho e alegre se sorri, e para um chorão se permanece sério, se queres que eu chore é preciso, antes de tudo, que você sofra ${ }^{2}$ (Orazio, 1983, p. 261).

Voltemos para a pergunta: Horácio está falando ao ator, como pretende uma longa tradição? Suponhamos por um momento que seja isso. Então nos perguntamos: o que ele exige do ator? Protesta talvez pelo direito de ser

Clelia Falletti, Si vis me flere. Emoções pelo espelho.

R.bras.est.pres., Porto Alegre, v.1, n.2, p. 286-300, jul./dez., 2011.

Disponível em http://www.seer.ufrgs.br/presenca 
emocionado cada vez que assiste a um espetáculo? E em que condição pretende isso? Para esclarecer melhor o nosso ponto de vista, nós elencamos duas hipóteses: de acordo com a primeira, ele pretende ser um simples espectador, e como tal está projetando as próprias emoções sobre $\mathrm{o}$ ator, atribuindo-as a ele $\mathrm{e}$ as presumindo, esperando que o ator esteja continuamente em poder das emoções - e afetado por elas ${ }^{3}$.

Mas a questão do ator não é tão trivial. E também seria banal demais para Horácio dar uma indicação desse gênero para um ator, justamente Horácio que tem o mito do longo aperfeiçoamento e da composição longamente meditada e elaborada até a exatidão daquilo que se quer exprimir.

Suponhamos então que ele esteja falando mesmo ao ator como poeta e artista. $\mathrm{Na}$ segunda hipótese, todavia, não devemos esquecer que Horácio, na sua qualidade de poeta e artista, nunca permitiu a expressão imediata do sentimento aparente. Devemos crer que ele sugeria ao ator não se comportar como verdadeiro artista? Certamente não. Poderíamos então ler naquele fragmento um preceito. Sempre que fala ao ator, ele lhe dá uma instrução técnica: o ator deve colocar-se em um estado criativo (um estado imaginativo), deixar que as emoções surjam nele e depois estudá-las e aprendê-las, para ser capaz de reproduzi-las em cena e sob controle. Esse poderia ser de verdade o equivalente ao ensinamento que faz ao poeta, de trancar em uma gaveta por nove anos qualquer coisa que tenha escrito sobre o ímpeto da emoção e limpá-la, revê-la, aperfeiçoá-la para que um desabafo pessoal não seja transformado em obra de arte.

É uma hipótese fascinante, mas o trecho não a sustenta e, quase certamente, Horácio não falava para um ator, embora o verso continue sendo citado como um preceito destinado àqueles que atuam no palco.

A advertência de Quintiliano em seu Institutio Oratoria (de cerca de 90 d.C) é certamente dirigida ao ator e ao orador. No sexto livro, após ter sublinhado a importância de provocar as emoções no público que ouve uma oração, uma peroração, um discurso, ele dá as regras para se obter isso. A primeira regra, desarmada (na sua

Clelia Falletti, Si vis me flere. Emoções pelo espelho.

R.bras.est.pres., Porto Alegre, v.1, n.2, p. 286-300, jul./dez., 2011.

Disponível em http://www.seer.ufrgs.br/presenca 
banalidade, e na inadequação por ser uma regra ou uma ajuda concreta) é a seguinte: “[...] é essencial, para provocar as emoções nos outros, na minha opinião, que o indivíduo as sinta primeiro em si" (Quintiliano, s/d) - e é o que disse, também, Horácio.

O orador, diz Quintiliano, é como o ator, e como o ator deve empenhar a sua capacidade inventiva de identificação para personificar e exibir emoções que não são suas, mas como se fossem suas, fazendo suas as emoções dos outros (que recria em si através da imaginação) e as transformando na eloquência do corpo e da voz.

Uma forte imaginação cria o evento em si (Fortis imaginatio generat casum) (Quintiliano, s/d) e as fortes visiones nutrem as paixões mais violentas, que pertencem à categoria retórica do pathos: a ira, o desgosto, o terror, o ódio, a dor, a piedade. Quando o ator/orador se identifica fortemente com tais paixões, o seu espírito as ganha sobre o corpo e lhe faz realizar aquilo que quer (nota-se o marcado dualismo mente-corpo, no qual a mente, o espírito, tem um domínio sobre o corpo). A mente, naquele instante, altera o estado físico, exteriormente e internamente.

E, nesse ponto, Quintiliano cita a sua experiência pessoal, com dois exemplos: relata ter visto frequentemente atores que deixavam o teatro ainda molhados de lágrimas após a interpretação de papéis patéticos nos quais se empenharam muito; e ele conta que eles estariam, por vezes, pessoalmente emocionados a tal ponto de explodir em lágrimas e inclusive tornarem-se pálidos, mostrando todos os sinais de dor genuína (Quintiliano, s/d). Em seguida, ele faz uma lista dos vários truques e artifícios dos quais se serve um orador para dar a ver as emoções na presença dos seus ouvintes encontrando-se, nesse momento, ele também a caminhar (como também os teóricos do teatro e da arte do ator) sobre o fio da navalha, a linha sutil e incerta que separa ou na qual se encontram - a técnica e a inspiração.

No entanto, com muita sabedoria, Quintiliano afirma que, embora a manifestação das emoções dependa da nossa capacidade de representar ou imitar as paixões, a

Clelia Falletti, Si vis me flere. Emoções pelo espelho.

R.bras.est.pres., Porto Alegre, v.1, n.2, p. 286-300, jul./dez., 2011.

Disponível em http://www.seer.ufrgs.br/presenca 
excelência mais alta, e insiste nisso, é obtida por uma delicada dose de espontaneidade (o deixar-se ir, o abandono - que é da natureza) e de premeditação (o estudo, a arte, o aperfeiçoamento - que é o artifício no sentido de feito para a arte $)^{4}$.

È sobre isso que foi baseada e desenvolvida toda uma série de reflexões que atravessou os séculos chegando à época de Garrick e Diderot.

As palavras de Horácio foram apenas um ponto de partida para mencionar o secular debate sobre o ator e a interpretação das paixões em teatro, para recordar a riqueza e a qualidade da discussão, que derivava sempre das ideias filosóficas correntes, das quais, em muitos casos, dependia o conhecimento biológico e científico do corpo humano 5 . Em um rápido e incompleto resumo recordamos, no século XVIII, as reflexões sobre o ator Luigi Riccoboni (pai) ${ }^{6}$ : para ele, o ator deve sentir aquilo que diz, deve capturar os tons da alma: não soa novo, mas Riccoboni está falando contra a interpretação retórica artificial pomposa, a declamação predominante em sua época. François Riccoboni (filho) diz o contrário, similar ao futuro Diderot de Paradosso dell'attore - e, como ele, se inspira em Garrick (Riccoboni, 1750). E muitos outros: Aaron Hill, em 1746, em seu Essay on the Art of Acting (Hill, 1753) centrado sobre o ator, lista os dez sentimentos fundamentais, os define, os analisa em termos de manifestações físicas. A seguir, começa a falar sobre a técnica do ator e diz que para o ator não se trata de imitação mecânica, mas que os sentimentos são criados primeiro pela imaginação que, por sua vez, influencia o aparato físico: gesticulação facial, músculos do corpo e voz. Samuel Foote, em Treatise on the Passions de 1747, centrado sobre o espectador, reverbera em Garrick e o seu A Short Treatise on Acting de poucos precedentes ${ }^{7}$. James Boswell, em On the Profession of the Player, de 1770, fala de dupla sensibilidade como uma fonte de "[...] poder misterioso pelo qual um ator é realmente o personagem que representa": as sensações e os sentimentos do personagem "[...] devem tomar posse plena, por assim dizer, da antecâmara da mente do ator,

Clelia Falletti, Si vis me flere. Emoções pelo espelho.

R.bras.est.pres., Porto Alegre, v.1, n.2, p. 286-300, jul./dez., 2011.

Disponível em http://www.seer.ufrgs.br/presenca 
enquanto o seu próprio caráter permanece nos mais íntimos esconderijos" (Boswell, 1770, p. 469-470).

Chega-se, assim, a Denis Diderot que, em $O$ Paradoxo do Comediante, primeiro sustenta a ideia de um ator emocionado (que não compõe), depois de um ator frio, que compõe, e dá o exemplo daquilo que acontece nele (dotado de sensibilidade comum e propenso a emocionar-se) e que gostaria que nunca acontecesse ao ator:

Se devo fazer uma narração um tanto comovente, me vem ao coração ou a cabeça não sei qual perturbação: me prende a língua, a minha voz se modifica, começo a dizer coisas sem conexão, o discurso pára. Após gaguejo e, quando percebo isso, as lágrimas escorrendo pelas bochechas, termino por silenciar (Diderot, 1960, p. 81-82).

No homem sensível, diz ele, o coração continuamente perturba a cabeça; no ator é a cabeça que às vezes leva ao coração uma perturbação passageira. "Nós sentimos", diz Diderot, "eles observam, estudam e transcrevem" (Diderot, 1960, p. 24). A sensibilidade é uma bela qualidade comum, mas não é a qualidade do gênio: não é o coração, é a cabeça que faz tudo "[...] e para a mínima circunstância imprevista, o homem sensível a perde [...]": o homem sensível não é bom para a cena.

As recentes descobertas da neurociência, hoje, atraem a nossa atenção novamente em direção à Horácio e se conectam perfeitamente com aquilo que diz o poeta e que é uma experiência aos olhos de todos (rimos e choramos com os outros).

Nós temos, no cérebro, um mecanismo espelho. Quando um sujeito realiza uma ação, há no seu cérebro a ativação de um determinado programa motor que lhe consente de executar aquela determinada ação - isto é claro: se não se ativa um programa motor, não há ação. Mas descobriu-se algo mais, algo surpreendente e inesperado que nos obriga a rever muitas ideias construídas e tidas como certas: quando nós observamos alguém que executa uma ação há uma ativação concomitante, no cérebro de quem observa, nas mesmas

Clelia Falletti, Si vis me flere. Emoções pelo espelho.

R.bras.est.pres., Porto Alegre, v.1, n.2, p. 286-300, jul./dez., 2011.

Disponível em http://www.seer.ufrgs.br/presenca 
áreas motoras incumbidas para a organização e execução daquela ação. Isso significa que, mesmo que nós não executemos aquela ação em primeira pessoa, todavia, no nosso cérebro se ativa um programa motor responsável por aquela ação que observamos no outro, como se nós realmente estivéssemos fazendo a ação que vemos (nos predispomos a executá-la, mesmo se não a fazemos, e isso significa que a fazemos de qualquer forma em nível de impulsos que permanecem tais e que, todavia, produzem toda uma série de alterações químicas - suor, produção de adrenalina etc. - de preparação para a ação, que retroagem sobre o nosso sistema nervoso central e que são as mesmas do sujeito que age). Em nível mais geral, acredita-se que esse mecanismo de espelhamento que nós temos, ao replicar dentro de nós o que o outro está fazendo, faz com que entendamos as intenções: como se lêssemos na sua mente ${ }^{8}$. A existência dessa função espelho foi descoberta na década de 1990 pela equipe científica liderada pelo professor Rizzolatti na Universidade de Parma. Os neurônios que nos fazem ressoar com os outros, foram por eles chamados neurônios-espelho ou mirror neurons.

E, agora, voltemos para a afirmação de Horácio: $S i$ vis me flere, dolendum est primum ipsi tibi.

Os testes científicos feitos em todo o mundo após a descoberta dos neurônios-espelho mostraram que o espelhamento não ocontece se na origem da ação não há uma intenção, ou seja, se for produzida por um sujeito artificial ou se o sujeito não estiver executando uma ação realmente sentida, mas fazendo simplesmente um gesto.

Os testes científicos mostraram ainda que há inclusive um espelhamento neural responsável pela partilha dos sentimentos e das emoções dos outros, e, portanto, também das emoções responsáveis pelo riso e pelo choro: os mesmos neurônios que se acendem no nosso cérebro quando experimentamos uma emoção, disparam também quando vemos a mesma emoção no outro. $\mathrm{Na}$ verdade, deveríamos dizer que nós vemos ou reconhecemos aquela emoção no outro porque $\mathrm{o}$ programa motor é ativado instantaneamente em nosso cérebro. Assim, podemos dizer que nós compartilhamos

Clelia Falletti, Si vis me flere. Emoções pelo espelho.

R.bras.est.pres., Porto Alegre, v.1, n.2, p. 286-300, jul./dez., 2011.

Disponível em http://www.seer.ufrgs.br/presenca 
com os outros um espaço comum de emoção - e um espaço comum de ação, mesmo se não fizermos, aparentemente, a mesma ação no espaço fora de nós (Rizzolatti; Sinigaglia, 2006).

Tudo isso é muito interessante para quem se ocupa de teatro: dos atores, dos espectadores e da sua relação. $\mathrm{O}$ espectador é tocado e reage aos estados emotivos e às ações que acontecem em cena. Desde que as ações e emoções das quais falamos não sejam emoções e ações falsas. Uma ação não intencional, uma emoção macacada, que não modifica o aparato bioquímico interno e o hipotálamo ou a ínsula no cérebro do ator, não tem nenhuma possibilidade de influenciar o sistema espelho neural nas mesmas áreas do cérebro do espectador.

A ação não fingida, mas ditada por uma intenção real, e a emoção não fingida, mas gerada em resposta às reais mudanças internas, produzem, ao contrário, em quem age, uma circularidade entre sistema nervoso central e periferia do corpo, um jogo incessante de trocas de informações e respostas (feedback) que não são nada mais do que as modulações recíprocas: "[...] o sistema nervoso central modula a atividade da periferia, a periferia do corpo modula a atividade do sistema nervoso central" (Ruggieri, 1997, p. 148) ${ }^{9}$.

É isso que acontece na vida cotidiana, sem necessariamente percebermos. Quando o ser humano sobe no palco, no entanto, deve reger tudo isso, deve ter conhecimento das modificações que acontecem em seu corpo-mente para poder dirigi-las e manter ligado em si o espectador e, assim, lhe fazer executar uma experiência.

Essa circularidade presente no sistema homem e, em seguida, no sistema homem-ator estende-se a uma circularidade que inclui o sistema intersubjetivo e, no teatro, o sistema ator-espectador, o sistema sala-cena ${ }^{10}$.

A primeira observação que salta à mente de quem se ocupa de teatro é a grande responsabilidade que pesa sobre um ator que se apresenta para uma plateia, e surge a pergunta: como pode o ator ir para a cena sem o training necessário não para interpretar um papel, mas para mover grandes forças, tanto dentro quanto fora de si mesmo?

Clelia Falletti, Si vis me flere. Emoções pelo espelho.

R.bras.est.pres., Porto Alegre, v.1, n.2, p. 286-300, jul./dez., 2011.

Disponível em http://www.seer.ufrgs.br/presenca 
Os modernos programas de treinamento do performer (tanto no campo do teatro quanto no da música, da dança e do esporte) são programas cada vez mais rigorosos, envolvendo técnicas refinadíssimas que exigem um trabalho árduo sobre si mesmo ${ }^{11}$, um trabalho de exploração e autoconhecimento, corpo-mente, e de extremo controle. Não se pode esquecer que o ator é, ao mesmo tempo, artista criador e obra criada, e que o seu trabalho é criado em presença de alguem e é, portanto, em um incessante fluir. O performer pode ser definido como uma obra de arte que atua sobre o usuário ao mesmo tempo que modula a si mesmo, e em uma circularidade de experiência.

No momento em que um performer assim treinado encontra o espectador, as suas ações reais (isto é, aquelas que comprometem em tempo real modificações no programa motor do seu próprio cérebro) provocam uma ativação (arousal) da mesma área do cérebro do espectador, cujo programa motor se ajusta, portanto, para executar as mesmas ações: o espectador reflete no próprio corpo as divagações, variações de direções, intenções, saltos, ritmos do performer. E tudo isso produz, no ator e no espectador, o sentimento: não é o sentimento que modifica o corpo, nos dizem as descobertas dos neurofisiologistas, mas são as modificações corporais que geram o sentimento ${ }^{12}$. O trabalho do ator é o de ter consciência e controle.

Em seu ensaio sobre Diderot, Copeau, entre outras coisas, diz que o verdadeiro paradoxo está no fato de que o ator é o artista que mais do que todos sacrifica a sua própria pessoa pela sua arte. "Não pode dar nada sem oferecer ele mesmo, não em efígie, mas a alma e o corpo, e sem intermediário. Sujeito e objeto, causa e fim, matéria e instrumento ao mesmo tempo, a sua criação é ele mesmo" (Copeau, 1971, p. 30). Esse é o mistério (o algo incompreensível da sua arte, o núcleo sobre o qual se atormenta - em cada século, e cada século com os instrumentos de sua própria cultura): como acontece que um ser humano, um ator, possa ser simultaneamente aquele que age e o resultado do seu agir. Trata-se, ao

Clelia Falletti, Si vis me flere. Emoções pelo espelho.

R.bras.est.pres., Porto Alegre, v.1, n.2, p. 286-300, jul./dez., 2011.

Disponível em http://www.seer.ufrgs.br/presenca 
mesmo tempo, de ser humano e marionete. Como conciliar esses dois opostos, este paradoxo:

$\mathrm{O}$ artista reina, serenamente, sobre a desordem de seu estúdio e dos seus materiais. Quanto mais a emoção aflui nele e o levanta, mais o seu cérebro se torna brilhante. Há compatibilidade entre esta frieza e este tremor, como na febre e na embriaguez [...] O absurdo do 'paradoxo' é de oferecer os procedimentos do ofício pela liberdade de sentimento e de negar, no artista, a sua coexistência e simultaneidade. O todo do ator é dar-se. Para dar-se é preciso primeiro que ele se possua. A nossa habilidade, com a disciplina que ela requer, com as reflexões que fixa e que controla, é a trama idêntica a nossa arte, com a liberdade que exige e as iluminações que encontra. A expressão emotiva decorre da expressão justa. Trata-se do suporte e da proteção. É graças ao ofício que podemos nos abandonar, porque é graças a ele que sabemos nos encontrar novamente (Copeau, 1971, p. 30-31).

A partir do preceito horaciano clássico, nós alcançamos as bases neurobiológicas das emoções no teatro. $\mathrm{Na}$ arte do ator - ou, mais geralmente: do performer - se reconciliam Apolo e Dionisio, o deus que simboliza a regularidade, a disciplina, as artes clássicas, e o deus que simboliza o abandono e o êxtase. Uma preparação pessoal fortemente disciplinada (um training) dá ao ator uma técnica e uma base na qual apoiar-se e sobre a qual contar para poder aventurar-se e abrir à improvisação - entendida no sentido do músico de jazz e que tem uma sólida estrutura e técnica que o autorizam a improvisar e, naquela improvisação feita em presença de alguém, lhe consente de recriar o fluxo e a qualidade emotiva da vida.

\footnotetext{
Notas

1 Jacques Copeau, intelectual, diretor, ator e professor de atores, 150 anos mais tarde intervém com suas Réflexions, prefácio para a edição de Paradoxe de Diderot, e assinala como Garrick que, naquela demonstração, estava simplesmente realizando um exercício como aqueles que fazem os alunos de uma escola, uma sequência de máscaras, realizada com um controle admirável, sem qualquer pretensão de interpretação: não encarnava um personagem, "mostrou-se sem doar-se" (Copeau, 1929).
}

Clelia Falletti, Si vis me flere. Emoções pelo espelho.

R.bras.est.pres., Porto Alegre, v.1, n.2, p. 286-300, jul./dez., 2011.

Disponível em http://www.seer.ufrgs.br/presenca 
2 "Non satis est pulchra esse poemata; dulcia sunto/et, quocunque volent, animum auditoris agunto/Ut ridentibus adrident, ita flentibus adflent/humani vultus; si vis me flere, dolendum est/primum ipsi tibi" (vv 99-104).

${ }^{3}$ Refiro-me a uma difusa atitude mental de etnocentrismo do espectador. "Quem ousa questionar a história e teoria da música, sem nem conhecer o $\mathrm{ABC}$ do piano? O que em nossa cultura muitas vezes bloqueou o conhecimento sobre o ator foi a presunção de saber. Críticos, teatrólogos, teóricos e filósofos como Hegel ou mesmo Sartre, tentaram interpretar os processos criativos dos atores partindo do pressuposto de saber o que estavam falando. Na realidade, submetiam-se ao seu etnocentrismo de espectadores. Muitas vezes, imaginavam um processo que era somente uma projeção enganosa vinda depois dos efeitos obtidos pelos atores nas mentes de seus espectadores [...]. Trata-se de uma atitude que perdura [...]" (Barba, 1993, p.70-71).

${ }^{4}$ Sobre o Institutio Oratoria de Quintiliano, ver a análise que faz, em relação à arte do ator, J.R. Roach no capítulo Changeling Proteus. Rhetoric and the passions in the Seventeenth century do seu importante estudo The Player's Passion. Studies in the science of acting, London \& Toronto, 1985, no qual trata as conclusões de Quintiliano à luz das teorias científicas da época fortemente influenciadas por Aristóteles (especialmente pela Rhetorica e pela De anima).

5 Referindo-se a muitos escritos sobre o assunto e, em particular, para intervenções de Luciano Mariti, mais recentemente em Appunti tra scienza e teatro, apresentação do número monográfico de "Biblioteca Teatrale" (n.s., 2004, n. 71-72, p. XIII -XXVII) dedicada as Forme del sentire performativo e, anteriormente em Scienza dell'uomo e scienza dell'attore, o longo e preciso ensaio introdutivo a J.J. Engel, Lettere intorno alla mimica (1818), Roma, 1993.

${ }^{6}$ Ver, de Luigi Riccoboni, Pensées sur la Declamation, Paris 1738, e o precedente Dell'Arte rappresentativa capitoli sei, Londres, 1728. Ver o número monográfico dedicado ao Teatro do Iluminismo da revista Quaderni di teatro, III (1981), n. 11; em particular, sobre Riccoboni e Rémond de Sainte-Albine e Diderot, ver F. Ruffini, Spessore alla storia: problemi degli attori e problematica sull'attore nel Settecento, $\mathrm{p}$. 73-89.

${ }^{7}$ D. Garrick, An Essay on Acting, Londres 1744, afirma na página 2 que a recitação "[...] ocorrendo com a ajuda e o apoio da articulação, dos movimentos do corpo e das expressões dos olhos, imita, assume ou finge as diferentes emoções mentais e físicas, que nascem dos vários humores, virtudes e vícios inerentes à natureza humana" (citado em M. Carlson, Theories of the Theatre. A historical and critical survey from the Greeks to the present, New York (1984), versão em italiano Teorie del teatro. Panorama storico e critico, Bolonha, 1988, p. 162). O lapidário Essay que inclui o brevíssimo A short treatise pode ser lido em Actors on Acting (1940), edição de T. and H. Chinoy, New York 1970, p. 133-135.

8 Considera-se que esse mecanismo também forneça as bases neurofisiológicas da aprendizagem e da comunicação.

${ }^{9}$ É uma modulação devido aos incessantes "[...] fluxos de informação sensorial cutânea (em várias formas: tátil, térmica, dor), proprioceptivo (proveniente de todos os músculos do corpo; a partir de proprioceptores especiais do ouvido interno pôstos pelo controle do equilíbrio etc.), vegetativa, auditiva, olfativa, gustativa"(Ruggieri, 1997, p. 149 ss.).

${ }^{10}$ O livro mencionado, So quel che fai, de um neurocientista (Giacomo Rizzolatti) e de um filósofo (Corrado Sinigaglia), significativamente abre citando um homem de teatro,

Clelia Falletti, Si vis me flere. Emoções pelo espelho.

R.bras.est.pres., Porto Alegre, v.1, n.2, p. 286-300, jul./dez., 2011.

Disponível em http://www.seer.ufrgs.br/presenca 
Peter Brook: "Algum tempo atrás Peter Brook disse em uma entrevista que com a descoberta dos neurônios espelho as neurociências começaram a entender aquilo que o teatro sempre soube. Para Peter Brook - continuam os autores - o trabalho do ator seria em vão se ele não pudesse compartilhar, além de qualquer barreira linguística ou cultural, os sons e os movimentos do seu próprio corpo com os espectadores, tornandoos parte de um evento que eles próprios devem contribuir para criar. Em relação a essa imediata partilha o teatro teria construído a sua própria realidade e sua própria justificação, e é para ela que os neurônios espelho, com a sua capacidade de ativar-se tanto quando se executa uma ação em primeira pessoa quanto quando se observa ela executada pelos outros, dariam base biológica" (p. 1). Os atores de teatro, o cientista e o filósofo concordam; a complexidade do vínculo que une o homem aos outros homens e a impossibilidade de "conceber um $e u$ sem um nós" são evidentes ao máximo no teatro. E o cientista e o filósofo concluem a sua premissa ao livro, citando Peter Brook, mais uma vez: "Como lembrava Peter Brook, além de toda a diferença linguística ou cultural, atores e espectadores estão unidos pelo viver as mesmas ações e emoções. [E eles concluem:] O estudo de neurônios-espelho parece oferecer-nos, pela primeira vez um quadro teórico e experimental unitário dentro do qual começar a decifrar esse gênero de coparticipação que o teatro coloca na cena e que de fato constitui o pressuposto de toda nossa experiência intersubjetiva" (p. 4).

${ }^{11} \mathrm{O}$ training do performer induz mudanças profundas na própria estrutura do Programa Motor do Cérebro. Essas mudanças induzem, por sua vez, desenvolvimentos além de toda presciência nos processos de Aprendizagem e Memória; assim, o estudo e a compreensão desses fenômenos interessam cada vez mais à sociedade em geral.

12 William James, fisiologista, psicólogo e filósofo, já o havia dito em The Principles of Psychology, New York, 1892, em um capítulo precioso sobre as emoções em que enuncia a teoria na qual a emoção segue, ao invés de causar, a sua expressão corporal (p. 1065 e seguintes). Citamos um trecho de um escrito de S.M. Ejzenštejn de 1937 coletado em Civiltà teatrale nel XX secolo, organizado por Fabrizio Cruciani e Clelia Falletti, Bologna 1986, com o título Il montaggio e l'attore: "O senso comum diz que se nos acontece um desastre, nós entristecemos, e choramos, se encontramos um urso nos assustamos e corremos, se formos insultados por um rival, nós ficamos bravos e ferimos. A hipótese que sustentamos aqui é que a ordem dessa sequência é incorreta, que um estado mental não é imediatamente introduzido por outro, que as manifestações corporais devem ser antepostas, por isso devemos razoavelmente afirmar que nós nos sentiamos tristes porque choramos, bravos porque ferimos, assustados porque trememos; e não choramos, ferimos ou trememos proque estamos tristes, com raiva ou assustados”(p. 171 e seguintes). Veja as observações de Ejzenštejn no seu Teoria generale del montaggio, organizado por Pietro Montani, Venezia, 1985.

\section{Referências}

BARBA, Eugenio. Appunti per i Perplessi. In: BARBA, Eugenio. La Canoa di Carta. Trattato di antropologia teatrale. Bologna: Il Mulino, 1993. P. 70-71.

BOSWELL, James. On the Profession of the Player. London Magazine, Londres, p. 469-470, set. 1770 .

Clelia Falletti, Si vis me flere. Emoções pelo espelho.

R.bras.est.pres., Porto Alegre, v.1, n.2, p. 286-300, jul./dez., 2011.

Disponível em http://www.seer.ufrgs.br/presenca 
COPEAU, Jacques. Réflexions d'un Comédien sur le Paradoxe de Diderot. Paris: Plon, 1929.

COPEAU, Jacques. Réflexions. In: CRUCIANI, Fabrizio. Jacques Copeau, o le Aporie del Teatro Moderno. Roma: Mario Bulzoni, 1971. P. 30-31.

DIDEROT, Denis. Paradoxe sur le Comédien. In: MONETA, Angelo (Org.). Paradosso sull'Attore. Milano: Rizzoli, 1960.

FOOTE, Samuel. A Treatise on the Passions so far as they Regard the Stage. London: C.Corbett, 1747.

HILL, Aaron. The Works of the Late Aaron Hill. London: British, 1753.

ORAZIO. Le Lettere. In: MANDRUZZATO, Enzo. (Org.). Le Lettere. Milano: Biblioteca Universale Rizzoli, 1983.

QUINTILIANO. Institutio Oratoria. s/d.

RICCOBONI, Antoine- François. L’Art du Théâtre. Paris: Chez C.F. Simon et Giffart, 1750 .

RIZZOLATTI, Giacomo; SINIGAGLIA, Corrado. So quel che Fai. Il Cervello che Agisce e i Neuroni Specchio. Milano: Cortina Rafaello, 2006.

RUGGIERI, Vezio. L'Esperienza Estetica. Fondamenti psicofisiologici per un'educazione estetica. Roma: Armando Editore, 1997.

Clelia Falletti é professora de teatro na Università di Roma 1 La Sapienza. Desde 1981 participa da ISTA (International School of Theatre Anthropology) dirigida por Eugenio Barba. É uma das pesquisadoras na área da historiografia teatral mais respeitadas da Itália com diversos artigos e livros publicados.

E-mail: clelia.falletti@uniroma1.it

Traduzido do original em italiano por Débora Geremia e revisado por Gilberto Icle

Recebido em junho de 2011 Aprovado em agosto de 2011

Clelia Falletti, Si vis me flere. Emoções pelo espelho.

R.bras.est.pres., Porto Alegre, v.1, n.2, p. 286-300, jul./dez., 2011.

Disponível em http://www.seer.ufrgs.br/presenca 